\title{
A THREE-DIMENSIONAL DISLOCATION MODEL FOR THE SAN FERNANDO, CALIFORNIA, EARTHQUAKE OF FEBRUARY 9, 1971
}

\author{
By M. D. TRIFUNAC
}

\section{ABSTRACT}

The data from five strong-motion accelerograph stations centered above and surrounding the fault are used to develop an approximate three-dimensional dislocation model for the San Fernando earthquake. In the resulting model, the dislocation originates near the instrumentally determined epicenter at a depth of $9.2 \mathrm{~km}$ and then propagates southward and upward with a velocity of $2 \mathrm{~km} / \mathrm{sec}$. Calculated dislocation amplitudes of about $10 \mathrm{~m}$ in the hypocentral region have been found to decay to about $1 \mathrm{~m}$ toward the center of the fault and then build up again to about $6 \mathrm{~m}$ just before the fault intersects the ground surface in the San Fernando Valley. The assumed fault area of $130 \mathrm{~km}^{2}$ and the assumed rigidity $\mu=3 \times 10^{11}$ dyne $/ \mathrm{cm}^{2}$ give a moment $M_{0}=1.53 \times 10^{26}$ dyne-cm. This study indicates that, with several strong-motion accelerographs suitably located in the epicentral region, it is possible to find a kinematic faulting process associated with the periods of ground motion which are longer than about 1 sec.

\section{INTRODUCTION}

One of the fundamental problems in strong-motion seismology is the determination of the spatial and temporal characteristics of seismic energy release from several measurements of ground motion close to the source. This is clearly a difficult inverse problem since, knowing the output of the system, one is faced with the task of finding the input. The description of the black box, which models the effects of the transmission path, is at best only approximately known (Hudson, 1972). Despite these difficulties, however, the inverse problem in strong-motion seismology will remain the focal point of research for many years, since it is only through a thorough analysis involving high-frequency measurements that it will be possible to understand the physical nature of the processes going on at the source of energy release.

The purpose of this paper is to explore the extent to which an earthquake source can be modeled by a simple dislocation model (Haskell, 1969) and to determine the frequency (or wavelength) bandwidth up to which an adequate representation by such a simple model is possible. To do this, we chose the San Fernando, California, earthquake of February 9,1971, since it is one of the most completely recorded and documented earthquakes to date (e.g., Trifunac and Hudson, 1971; Jennings, 1971; USGS Profess. Paper 733, 1971).

\section{Summary of Field Observations, Aftershock Studies, and Previous Source Mechanism Work}

It has already been pointed out (e.g., Trifunac, 1972b) that the geometry of faulting during the San Fernando earthquake was more complicated than that for many other shocks in Southern California. Preliminary studies by Whitcomb (1971) and Wesson et al. (1971) indicated a tentative fault surface striking $\mathrm{N} 64^{\circ} \mathrm{W}-\mathrm{N} 72^{\circ} \mathrm{W}$ and dipping about $50^{\circ}$ toward the north. The extent of this dislocation was outlined by the aftershocks 
recorded in the first month following the main shock (Allen et al., 1971) and could be represented by an area of about 15 by $15 \mathrm{~km}$. Kamb et al. (1971) indicated very shallow $\left(20^{\circ}-25^{\circ}\right)$ thrusting of the fault plane where it breaks the surface, along the Tujunga and Sylmar segments with more steeply dipping, about $65^{\circ}$, en echelon faulting to the north of the main breaks. The analysis of selected aftershocks (Whitcomb, 1971; Hanks et al., 1971) indicated that following the main shock the upper crustal block was still breaking upward and southwestward along the main dislocation surface. On the other hand, leftlateral motion was predominantly indicated along the southwestern aftershock zone (Figure 1). This general pattern of motion agreed with the preliminary reports on the

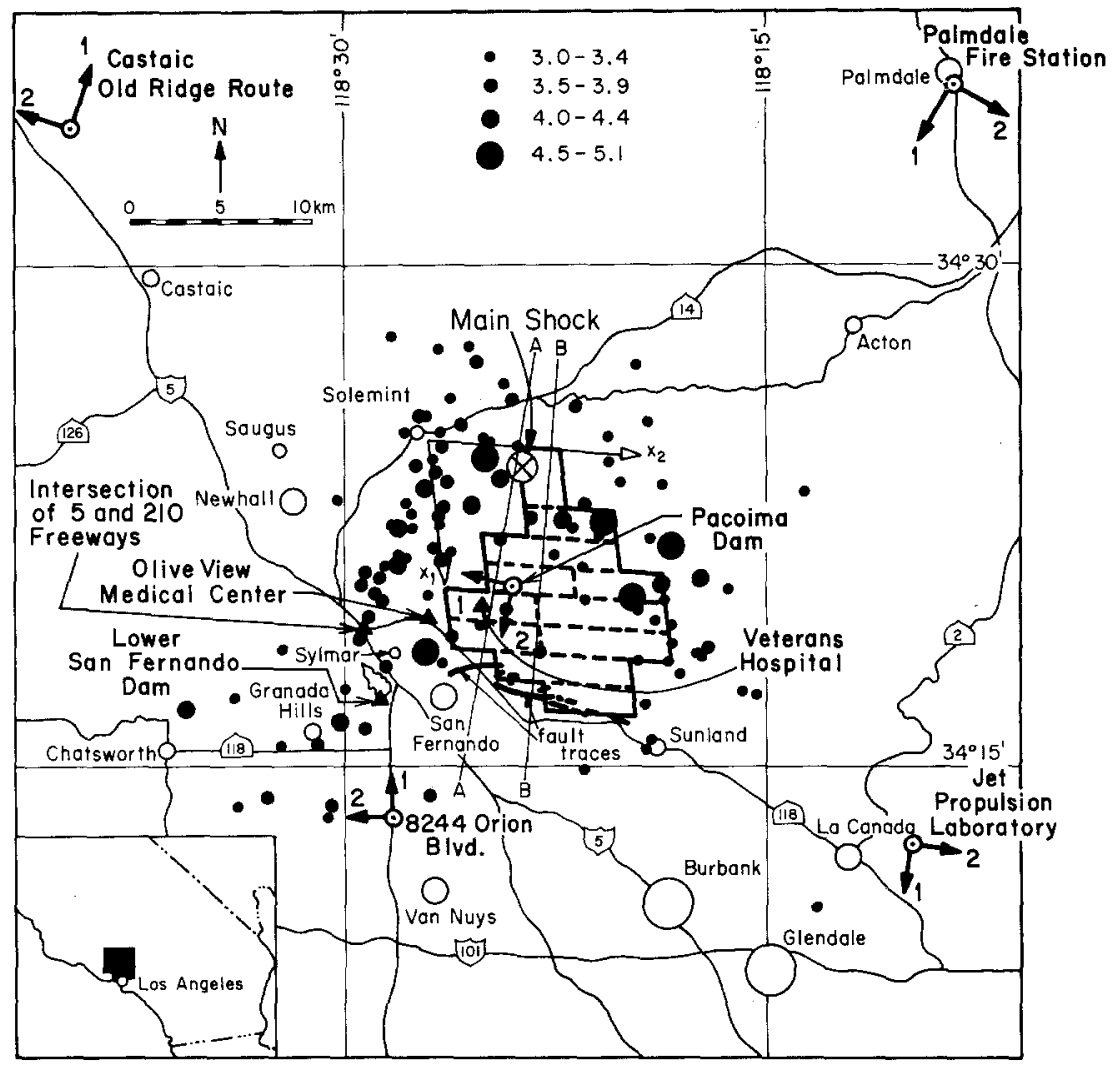

FIG. 1. Map of epicenters of the main shock and the aftershocks of the San Fernando Earthquake, of magnitude 3.0 and greater, for February 9 through March 1, 1971 (redrawn from Allen et al., 1971). Also shown are (1) the horizontal projection of the dynamic dislocation model and (2) the five sites of the strong-motion accelerograph stations that provided the data for this study.

observed surface faulting (Burford et al., 1971; Kamb et al., 1971; Lahr et al., 1971) which indicated that the overall fault motions were thrusting of the north side approximately to the southwest with nearly equal vertical uplift and left-lateral slip. The field observations indicated a total displacement of about $2 \mathrm{~m}$ along the observed surfacefault breaks in the San Fernando and Tujunga regions (Figure 2).

The strong-motion accelerograms recorded at the Pacoima Dam site (Figure 1; Trifunac and Hudson, 1971) provided, for the first time, unique data that could be used for the near-field source-mechanism studies (Trifunac, 1972b). (During the course of this study it was learned that the horizontal component directions for the Pacoima Dam 


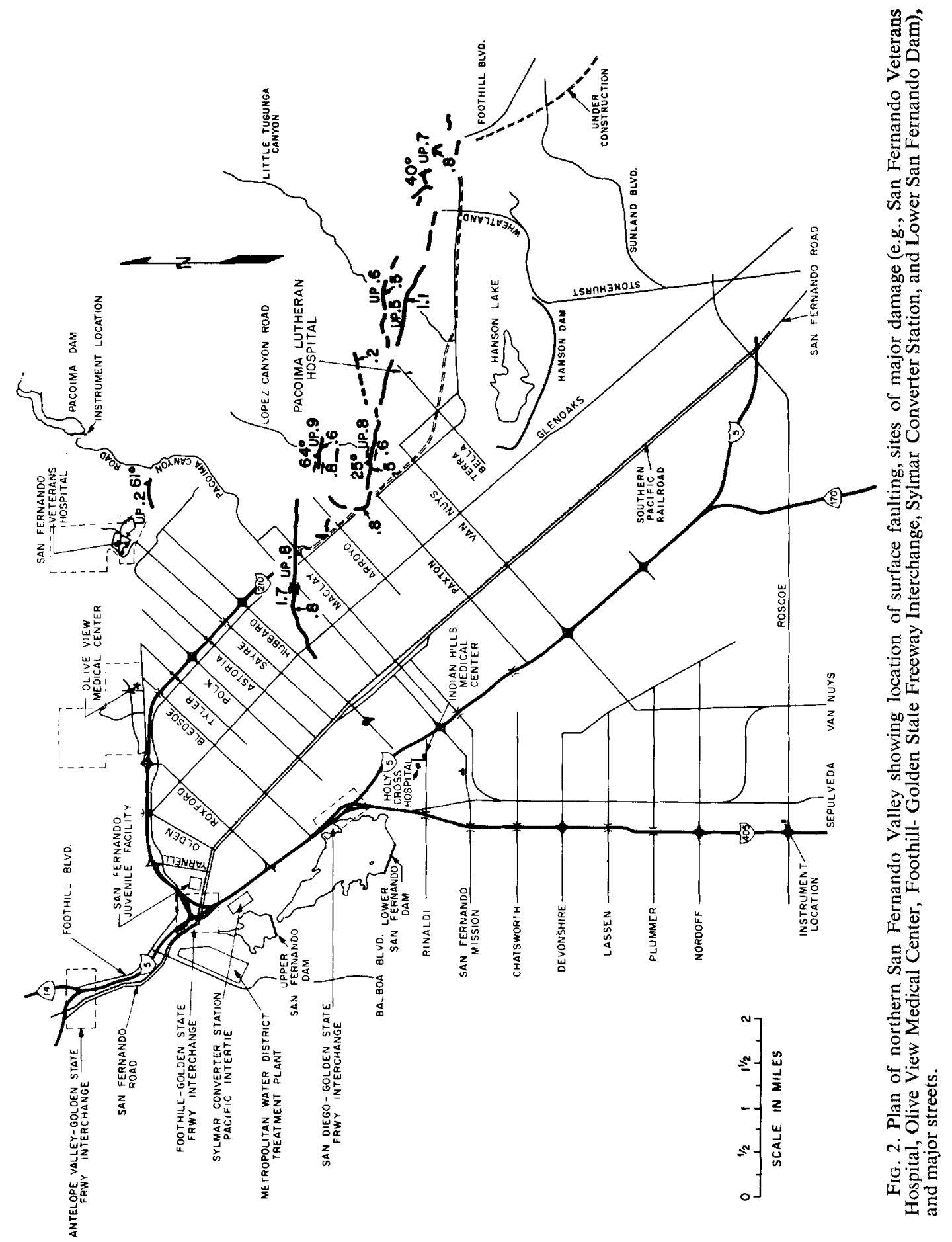


accelerogram reported by the SFS of NOAA to be $\mathrm{S} 16^{\circ} \mathrm{E}$ and $\mathrm{S} 74^{\circ} \mathrm{W}$ are incorrect. The correct directions are $\mathrm{S} 15^{\circ} \mathrm{W}$ and $\mathrm{N} 75^{\circ} \mathrm{W}$, respectively. This correction should be introduced into the paper by Trifunac and Hudson (1971) and the standard data report EERL 71-20 issued by the Earthquake Engineering Research Laboratory of California Institute of Technology.) By fitting the approximate near-field spectra, proposed by Brune (1970), to the displacement spectra calculated from the Pacoima Dam accelerogram, it was possible to estimate the average effective stress (the difference between the stress before the earthquake and the frictional stress which acts to resist the fault slippage) to be about 85 bars. Other source parameters (Trifunac, 1972b) were found to be: (1) stress drop $\Delta \sigma \approx 60$ bars, (2) apparent stress $\eta \bar{\sigma} \approx 34$ bars, (3) seismic moment $M_{0}=1.5 \times 10^{26}$ dyne-cm, and $(4)$ the seismic energy $E_{s} \approx 1.7 \times 10^{22}$ dyne-cm. These results favorably agreed with several other independent estimates summarized in Table 1. With the exception of Mikumo's results (1973) and our present study, all of the results in Table 1 are of a static nature since they are based on the asymptotic low- and highfrequency spectral amplitudes giving the estimates of moment and stress drop.

The changes in the horizontal and vertical position of the geodetic stations in the area affected by the San Fernando earthquake were measured and interpreted by Savage et al. (1972). They found that the measurements are roughly consistent with a simple dislocation model which can be described as follows: fault length along strike, $15 \mathrm{~km}$; fault width, $8 \mathrm{~km}$; depth to top of fault, $0.75 \mathrm{~km}$; dip, $45^{\circ} \mathrm{N} 10^{\circ} \mathrm{E}$; reverse slip, $2 \mathrm{~m}$; and left slip, $2 \mathrm{~m}$. The difficulty, that this simple fault model yields too narrow a fault width, has been interpreted by Savage et al. (1972) to mean that perhaps the slip decreases downward along the fault surface, approaching zero near the hypocenter.

Alewine and Jordan (1972) applied a generalized inversion scheme to the postearthquake static displacement fields. Their three-dimensional model, including the splay faults near the surface and the San Gabriel Fault, about $7.5 \mathrm{~km}$ north from the main surface rupture, leads to dislocation amplitudes that rise from about $2 \mathrm{~m}$ near the surface rupture to about $4 \mathrm{~m}$ at a depth of $1.5 \mathrm{~km}$, then decrease to about $1 \mathrm{~m}$ at a depth of $5 \mathrm{~km}$ and build up again to about $4 \mathrm{~m}$ near the hypocenter at a depth of about $10 \mathrm{~km}$. The two-dimensional finite element model of Jungels (1973), based on the same displacement data, leads to dislocation amplitudes similar to those of Alewine and Jordan (1972) with large displacement down to a depth of $10 \mathrm{~km}$ and then linearly going to zero at a depth of $14 \mathrm{~km}$.

Following the San Fernando earthquake, numerous questions were raised about the validity of the high-frequency amplitudes of the recorded ground acceleration near Pacoima Dam. Since this record plays the prominent role in the present work, it may be noted here that several simplified analyses (Trifunac, 1973; Boore, 1972; Reimer et al., 1972) have indicated that the amplitudes of the intermediate frequency waves (approximately $f>1 \mathrm{~Hz}$ ) may have been altered by the irregular surface topography, perhaps by about 20 to 50 per cent, whereas the high-frequency waves (approximately $f>10 \mathrm{~Hz}$ ) may have been affected by as much as 100 per cent. As will be seen in the subsequent sections of this paper, our model of the San Fernando earthquake will be restricted to the long-period waves only $(f<1 \mathrm{~Hz})$ so that the effects of surface topography on the interpretation of the recorded ground motions may be neglected.

A simple three-dimensional dynamic dislocation model for the San Fernando earthquake was already considered by Mikumo (1973). Although his method is similar to the approach taken in this paper, we believe that a more detailed analysis is now justified since Mikumo based his work essentially only on the Pacoima Dam accelerogram. In this paper, five stations are used in a search for the "best" dislocation model. 


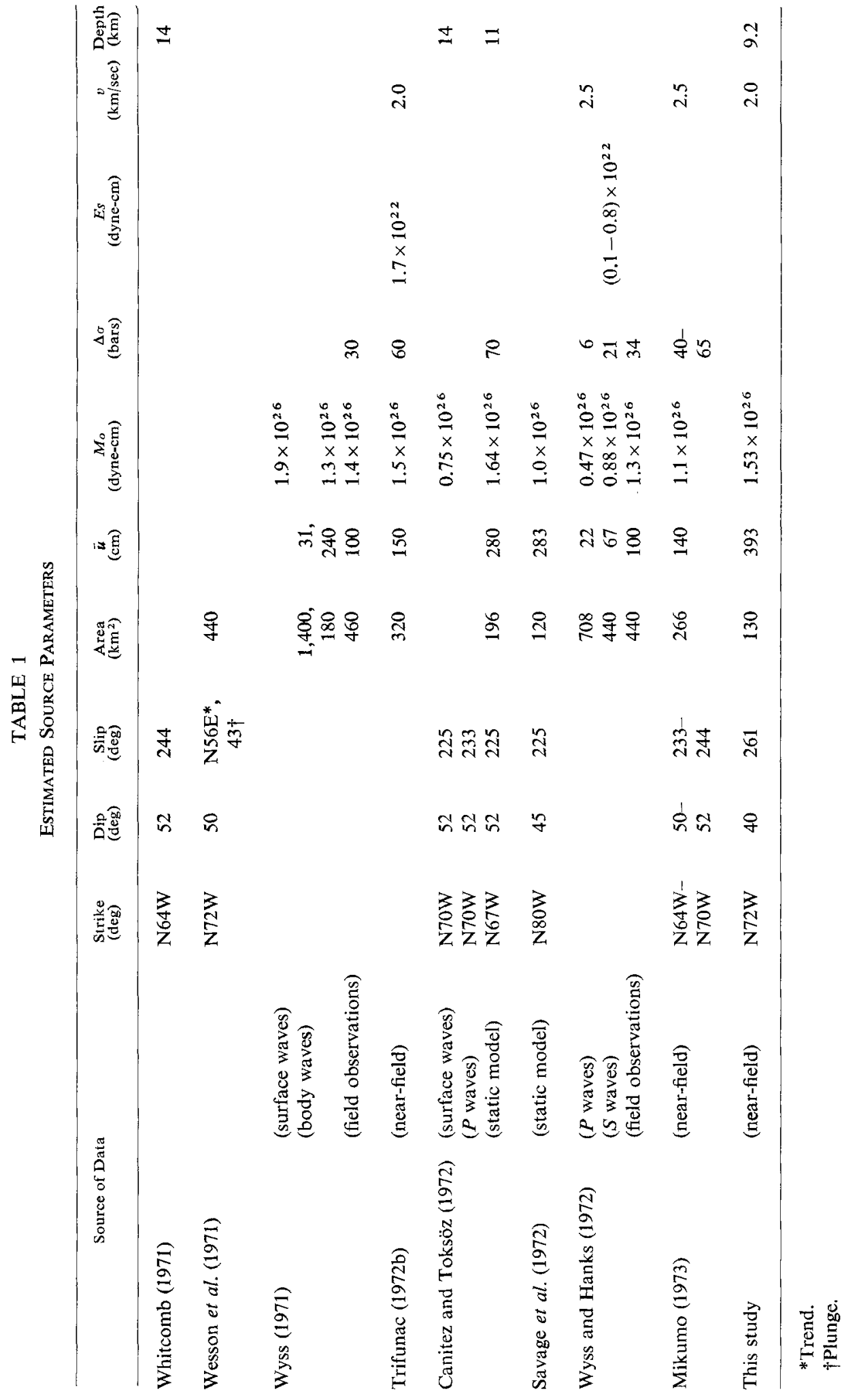




\section{A Simple Dislocation Model}

Solutions to the dynamic-crack problems are complicated by the nature of the mixed boundary-value problems and the necessity to deal with two types of motions coupled by a stress-free surface. Consequently, the number of known solutions is very small (e.g., Kostrov, 1970; Burridge and Willis, 1969; Richards, 1973). Also, the geological complexity of the Earth's crust, in which shallow destructive earthquakes occur, limits our ability to resolve accurately the waves emitted by a seismic source. This is because the waves, which are shorter or comparable to the size of the surrounding geological formations, have their amplitudes significantly modified by scattering and diffraction. In the light of these difficulties and the fact that still very little is known about the mechanisms that lead to the energy release, we choose to study the near-field ground motions recorded during the San Fernando earthquake only in the framework of the simple dislocation model developed by Haskell (1969). In spite of its simplicity, this model should give us an insight into the physical nature of the problem and, at the same time, may serve as a starting platform for more accurate and complete models in the future.

A form of the elastodynamic representation theorem (de Hoop, 1958) appropriate for the representation of faulting in an infinite homogeneous medium has been given by Haskell $(1964,1969)$ as follows

$$
u_{i}(x, t)=-\int_{s}\left\{\rho\left(\alpha^{2}-2 \beta^{2}\right) n_{j} M_{i g, g}\left[D_{j}\right]+\rho \beta^{2}\left(n_{g} M_{i j, g}\left[D_{j}\right]+n_{p} M_{i p, g}\left[D_{g}\right]\right)\right\} d S
$$

where

$$
\begin{aligned}
S & =\text { fault plane } \\
u & =\left(u_{1}, u_{2}, u_{3}\right)=\text { cartesian components of displacement } \\
x & =\left(x_{1}, x_{2}, x_{3}\right)=\text { cartesian coordinates of the point at which } u \text { is to be evaluated } \\
t & =\text { time } \\
\rho & =\text { density } \\
\alpha & =P \text {-wave velocity } \\
\beta & =S \text {-wave velocity } \\
n & =\left(n_{1}, n_{2}, n_{3}\right)=\text { unit normal on } S \\
D & =\left(D_{1}, D_{2}, D_{3}\right)=\text { displacement discontinuity on } S \\
M_{i j, q} & =\text { an operator given by Haskell (1969) [p. 806, equation (2)]. }
\end{aligned}
$$

For shear faults, $D$ lies in the fault plane and $n_{j} D_{j}=0$. Choosing $\left(x_{1}, x_{2}\right)$ to be the fault plane $\left(n_{i}=\delta_{i 3}, D_{3}=0\right), u$ may be separated into the two linearly independent parts $u=u^{(1)}+u^{(2)}$ where $u^{(1)}$ results from $D_{1}$ and $u^{(2)}$ results from $D_{2}$. Assuming that the dislocation starts at the same time at all points along the $x_{2}$ axis (Figure 3 ) and propagates with uniform velocity $v$ in the positive $x_{1}$ direction, we can write

$$
D_{i}\left(\xi_{1}, \xi_{2}, t\right)= \begin{cases}0 & ; t-\frac{\xi_{1}}{v} \leq 0 \\ \left(D_{i o} / T\right)\left(t-\xi_{1} / v\right) & ; 0 \leqq t-\frac{\xi_{1}}{v} \leqq T . \\ D_{i o} & ; t-\frac{\xi_{1}}{v} \geq T\end{cases}
$$


Here $\xi=\left(\xi_{1}, \xi_{2}, \xi_{3}\right)$ are the cartesian coordinates of the point of integration, $T$ is the rise time of the dislocation at a point $\underline{\xi}$, and $D_{i o}$ are the final (constant) dislocation amplitudes.

A model of a rectangular shear fault of length $L$ and width $H$ then can be represented as in Figure 3. The fault lies in a plane striking $\mathrm{E} \theta^{\circ} \mathrm{S}$ and dipping $\psi^{\circ} \mathrm{N} \theta^{\circ} \mathrm{E}$. The direction $x_{1}$ of the progressing plane dislocation front, traveling at the velocity $v$, is given by $\phi$ while the final slip direction depends on the amplitudes $D_{1}$ and $D_{2}$.

To calculate the three displacement histories $u$ at any point $x$, equation (1) has to be integrated numerically, once over the entire surface $S$ for every displacement component and at a given fixed time. To do this, Haskell (1969) used the Gauss' method of numerical integration but encountered a serious "numerical noise" problem. In this work, we found

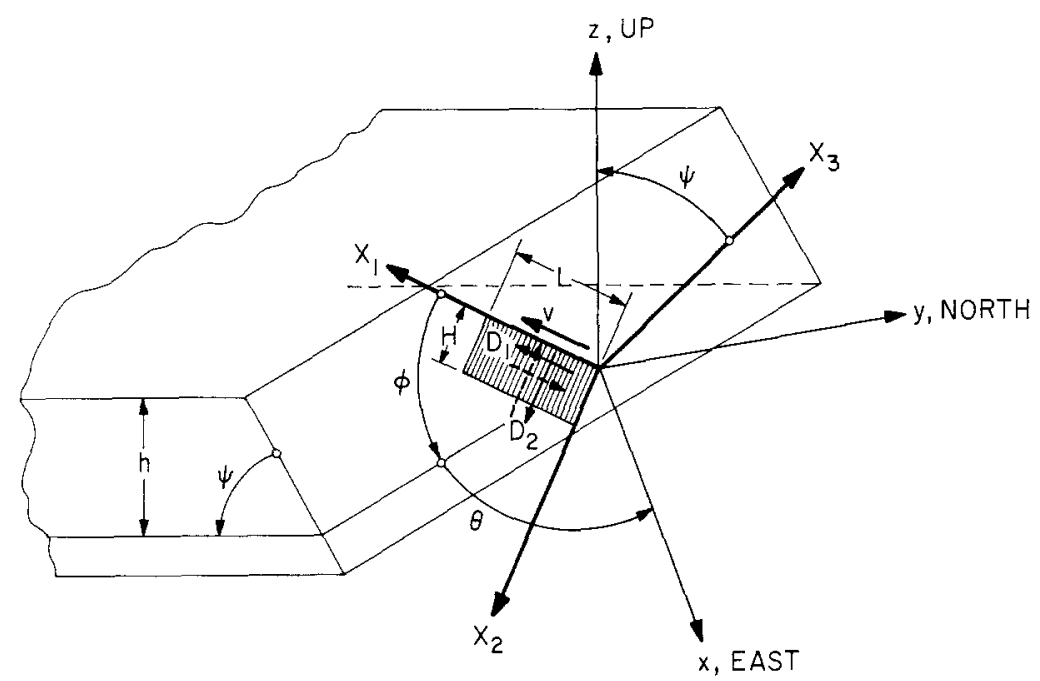

Frg. 3. Geometrical setting of an elementary fault model.

that this noise can be eliminated by integrating over a grid of unequally spaced points that are evenly distributed between the jumps of the integrand of equation (1) and along the $x_{1}$ axis. The integration scheme adopted consists of applying the Simpson's $1 / 3$ rule (e.g., Salvadori and Baron, 1961) to $N, \Delta H$-wide strips along the $x_{1}$ axis and then again to $3 N, \Delta H / 3$-wide, strips along the $x_{1}$ axis. If the result of integrating with $\Delta H$-wide strips is designated by $A_{1}$ and that of integrating over $\Delta H / 3$-wide strips is designated by $A_{3}$, then using the Richardson's $(\Delta H)^{2}$-extrapolation scheme, the improved result $A_{1,3}$ becomes

$$
A_{1,3}=-0.125 A_{1}+1.125 A_{3}
$$

(Salvadori and Baron, 1961). Equation (3) was used in all computations presented in this paper.

It is noted here that the representation (1) is the exact solution for a homogeneous infinite medium only, and that it, therefore, cannot be compared exactly with ground motions recorded in a semi-infinite inhomogeneous medium. We may assume, however, that the wave amplitudes are approximately doubled by the free-surface effect. Furthermore, the undispersed Rayleigh waves supported by the semi-infinite space do not exist in the absence of the free surface. Therefore, the representation (1) can be used to model 
approximately the recorded near-field motions and the body-wave motions only. Although it appears that the above assumptions are crude and that the surface waves perhaps should not be neglected in the modeling of the recorded strong ground motion at or near the source, the prominence of the surface waves at great distances comes from their $1 / \sqrt{ } r$ amplitude decay as compared to the $1 / r$ decay for body waves and not necessarily from their amplitudes being larger than body-wave amplitudes to begin with. In the near-field, ground-motion terms decaying like $1 / r^{4}, 1 / r^{2}$, and $1 / r$ and having the relative amplitudes at the source proportional to 30,12 , and 2 , respectively, are expected to dominate in the observed motions.

In the case of a vertical surface fault with strike-slip motion, the stress-free boundary conditions at the free surface are approximately satisfied when the infinite space model with double fault width is used. For a thrust fault, however, the thrusting block of the mirror-image fault above the half-space boundary would crush down against the thrusting block below the same boundary. The single thrust fault model in the infinite space used in this study with the doubled amplitudes to account for the free-surface effect, also violates the free surface boundary conditions. In spite of these difficulties, we feel that it is appropriate to examine the extent to which these approximations might be used for interpretation of the recorded ground motions.

\section{Strong-Motion Accelerograph Data}

The 250 accelerograms recorded during the San Fernando, California, earthquake of February 9, 1971, represent the largest collection of strong-motion data ever compiled from a single earthquake. These data contain more than 175 records from the Los Angeles area, 20 to $50 \mathrm{~km}$ from the epicenter, and include 57 high-rise building sites with each site consisting of 2 or 3 stations (one instrument in the basement, roof, and an intermediate floor).

To find the details of the source mechanism, it is necessary to have the strong ground accelerograph stations close to and surrounding the fault. By analyzing these motions near the fault, it is then possible to minimize the unwanted effects of the transmission path. By having the stations that surround the fault, better control of the inferred directions of the slip vector and the dislocation spreading is feasible.

The five stations selected for the least-square fitting of the dislocation amplitudes are listed in Table 2 together with the accelerograph types and the characteristics of each transducer. Typically, the strong-motion recorder is an accelerograph with an optical recording transducer which can be represented by a viscously damped single-degree-offreedom system. Since the natural frequency of such an instrument is usually between 15 and $25 \mathrm{~Hz}$ (Table 2), its analog output approximates the absolute acceleration of the instrument base in the frequency range between 0 and about $10 \mathrm{~Hz}$. Prior to analysis, such an analog signal has to be converted to the digital form, but, before one can proceed with the analysis, it is also necessary to determine the frequency band in which the available data represent the actual ground motion accurately. The detailed analysis of digitization processes (Trifunac et al., 1973a) and the methods for instrument (Trifunac, 1972a) and base-line corrections (Trifunac, 1971a) indicate that typical accelerograms represent the absolute ground motion accurately in the frequency band between 0.07 $\mathrm{Hz}$ and $25 \mathrm{~Hz}$. While the high-frequency limit of $25 \mathrm{~Hz}$ does not seem to impose serious restrictions for most analyses, the present low-frequency limit of about $0.07 \mathrm{~Hz}$ imposes some limitations on the near-field source mechanism studies since it rules out the measurement of permanent displacements. 
TABLE 2

INSTRUMENT TYPes AND ChaRACTERISTICS

\begin{tabular}{|c|c|c|c|c|}
\hline $\begin{array}{c}\text { Station } \\
S \text {-Time (sec) }\end{array}$ & Component & $\operatorname{Tn}(\mathrm{sec})$ & $\underset{\text { Damping }}{\text { Dritical }}$ & $\begin{array}{l}\text { Instrument } \\
\text { Type }\end{array}$ \\
\hline Pacoima Dam, 2.1 & $\begin{array}{l}\mathrm{N} 75^{\circ} \mathrm{W} \\
\text { S15 } \\
\text { Down }\end{array}$ & $\begin{array}{l}0.053 \\
0.051 \\
0.052\end{array}$ & $\begin{array}{l}56.8 \\
54.4 \\
58.8\end{array}$ & AR-240 \\
\hline 8244 Orion Blvd., 1st floor, 3.0 & $\begin{array}{l}\text { North } \\
\text { West } \\
\text { Down }\end{array}$ & $\begin{array}{l}0.054 \\
0.053 \\
0.053\end{array}$ & $\begin{array}{l}57.8 \\
58.5 \\
58.6\end{array}$ & AR -240 \\
\hline Jet Propulsion Laboratory basement, 3.0 & $\begin{array}{l}\text { S } 8^{\circ} \mathrm{W} \\
\text { S } 82^{\circ} \mathrm{E} \\
\text { Down }\end{array}$ & $\begin{array}{l}0.047 \\
0.046 \\
0.046\end{array}$ & $\begin{array}{l}60.1 \\
57.2 \\
61.2\end{array}$ & RFT -250 \\
\hline Palmdale Fire Station, 1.7 & $\begin{array}{l}\mathrm{S} 60^{\circ} \mathrm{E} \\
\mathrm{S} 30^{\circ} \mathrm{W} \\
\text { Down }\end{array}$ & $\begin{array}{l}0.047 \\
0.048 \\
0.049\end{array}$ & $\begin{array}{l}50.8 \\
63.2 \\
61.8\end{array}$ & RFT-250 \\
\hline Castaic Old Ridge Route, 0 & $\begin{array}{l}\mathrm{N} 21^{\circ} \mathrm{E} \\
\mathrm{N} 69^{\circ} \mathrm{W} \\
\text { Down }\end{array}$ & $\begin{array}{l}0.053 \\
0.051 \\
0.052\end{array}$ & $\begin{array}{l}59.2 \\
63.6 \\
57.7\end{array}$ & AR-240 \\
\hline
\end{tabular}

\section{Finding THE "Best” Dislocation Model}

To find the dislocation model that fits the observed ground motions at the five strongmotion accelerograph stations surrounding the San Fernando earthquake (Figure 1), we perform the following steps:

1. Choose the hypocenter where the dislocation will be initiated. This point (or a short line, Figure 1) might be located in the vicinity of the instrumentally determined focus.

2. Assume the shape and the position of the final fault plane and approximate it by a finite number $(k=1,2, \ldots, K)$ of rectangular "elementary faults" (Figure 4). Although it is not necessary, it may be convenient to orient the rectangular elementary faults so that the $x_{1}$-coordinate axis is parallel to the direction in which the plane dislocation [e.g.; equation (2)] propagates. For simplicity, in this analysis, we shall work with plane dislocation fronts only and shall assume that at any point on the fault surface the dislocation amplitude changes in time according to equation (2). While these assumptions reduce the number of parameters that describe the dislocation growth in time, they are clearly not essential to the basic nature of the analytical approach.

3. Assume that each elementary fault has the dislocation amplitude $D_{10}=1$ and $D_{20}=0$ [see equations (1) and (2)] and calculate, using the representation (1), the complete time histories $u_{i, j, k, l}$ for $k=1,2, \ldots, K$ and $l=1,2,3, \ldots, L$ ( $\left.L=t_{o} / \Delta t\right)$ for three $(i=1,2,3)$ mutually perpendicular components of ground motion at all $(j=1,2,3, \ldots, J)$ points where strong-motion data are available. Here $t_{o}$ is the total time interval to be considered and $\Delta t$ is the spacing between the two consecutive time coordinates. Of course, the directions for which ground motions are calculated at every observation point $j$ should coincide with the direction of actual measurement. The next step is to repeat the whole procedure for $D_{10}=0$ and $D_{20}=1$ to get $u_{i, j, k, l}$ for $k=K+1, K+2, \ldots, 2 K$.

4. To find the optimum dislocation amplitudes $a_{k}, k=1,2, \ldots, 2 K$, use the leastsquares criterion which leads to the following $2 K$ linear equations. 


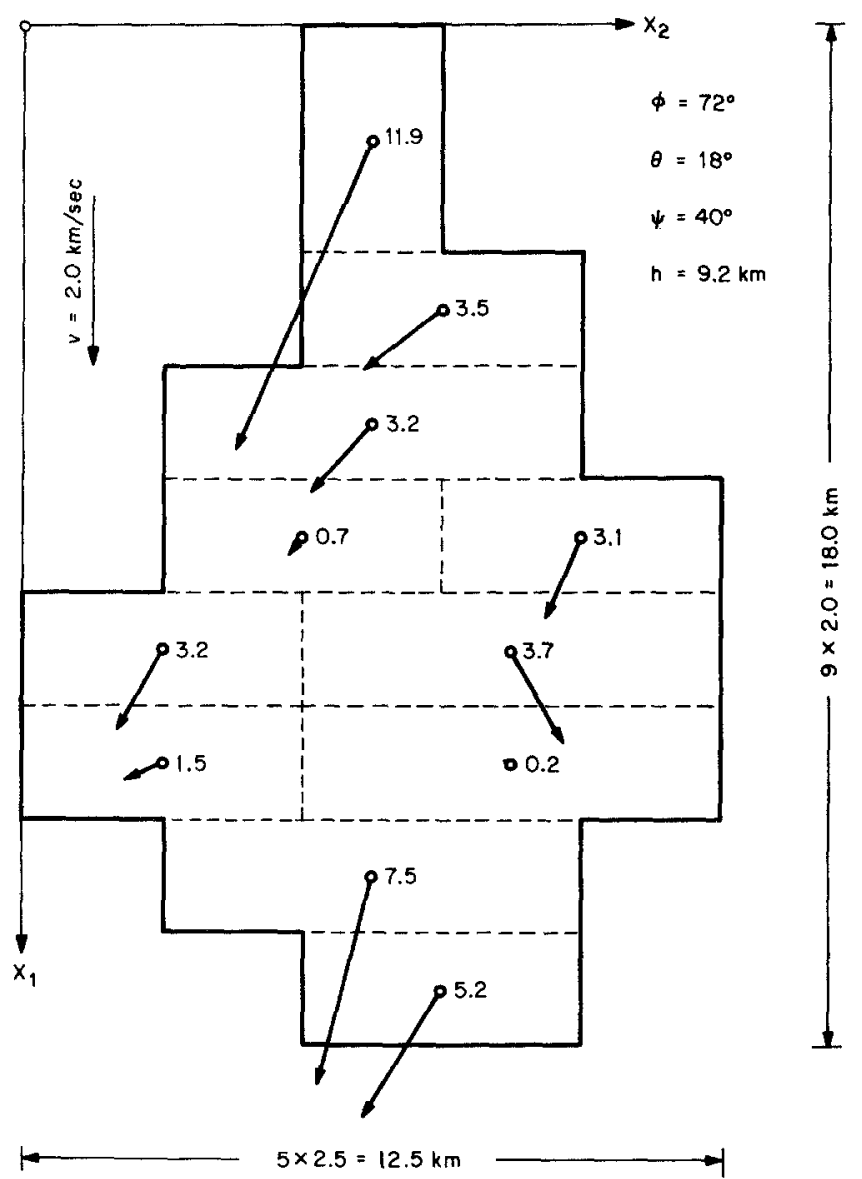

SCALE FOR DISLOCATION AMPLITUDES

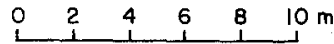

FIG. 4. Selected fault shape and the inferred dislocation amplitudes (averaged over the eleven rectangular areas) for the San Fernando earthquake of February 9, 1971.

where

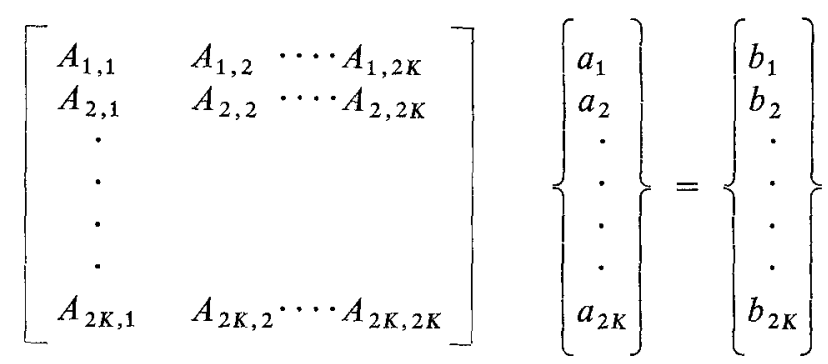

$$
\begin{aligned}
A_{m, m} & =\sum_{i=1}^{3} \sum_{j=1}^{J} \sum_{l=1}^{L} u_{i, j, m, l}^{2} \\
A_{m, n} & =\sum_{i=1}^{3} \sum_{j=1}^{J} \sum_{l=1}^{L} u_{i, j, m, l} u_{i, j, n, l} \\
b_{m} & =\sum_{i=1}^{3} \sum_{j=1}^{J} \sum_{l=1}^{L} u_{i, j, m, l} U_{i, j, l} .
\end{aligned}
$$


$U_{i, j, n}$ is the measured ground motion in the $i$ th direction, at the $j$ th station, and at time $t=(n-1) \Delta t$.

In spite of the fact that the above outlined scheme gives a way of finding the best set of $a_{k}$ 's, it does not represent a complete inverse problem approach, since the final fault shape, the dislocation velocity $v$, its direction, and the dislocation rise time $T$ have to be guessed. For most earthquakes, however, classical methods of teleseismic seismology give the approximate and overall estimates for the slip direction and the orientation of the fault plane, while the recent theory of Brune (1970) based on the spectra of the far-field body-wave motions appears to give an estimate of the final source dimensions (Trifunac, $1972 \mathrm{~b}, \mathrm{c})$. When this information is combined with the data on the surface-fault expressions (e.g., Kamb et al., 1971) and the detailed distribution of aftershocks following the main energy release (e.g., Allen et al., 1971; Hanks et al., 1971), the search for the best dislocation model is significantly simplified, since the intervals of possible parameter variations are substantially reduced. The method for finding the "best" dislocation model as presented in this paper is self contained in that, when no other independent source parameter determinations are available, more detailed and extensive search should always give the "best" dislocation model. This is, of course, based on the working assumption that one is willing to accept that the dislocation model expressed by the representation (1) is capable of explaining the basic physics of the faulting process. The future research will, no doubt, give an improved representation that will satisfy the halfspace boundary conditions exactly and will eventually be able to incorporate the contributions from surface waves and the effects of varying geological strata along the transmission path.

The representation (1), described by Haskell (1969) and used in that same form in his work, gives displacements versus time for the postulated dislocation on the fault. By the straightforward differentiation of (1), it is possible to work with the velocities or accelerations as well. In this study, however, we choose to use the ground displacements. Some of the underlying reasons for this decision can be summarized as follows. The waves emitted from the source are scattered and diffracted by numerous geological discontinuities and surface topography irregularities, and the extent to which these waves are modified is governed by the ratio of the size of the irregularity to the wavelength. Studies of some of these effects show (e.g., Trifunac, 1971b; Trifunac, 1973; Boore 1972) that the waves long compared to the characteristic dimensions of the discontinuities are less affected. Since the modeling of the irregular geological formations between the source and the receiver is beyond the scope of this study, it becomes essential, then, to devise a scheme which will depend primarily on the long-period waves. Since each integration acts like a $1 / \omega$ filter, the ground displacements are better suited for our present analysis than ground velocity or acceleration measurements.

Another important consideration is related to the selected grid size on the fault and the feasible variation of the details of what went on at the fault. Undoubtedly, the degree of complexity of the faulting process that we can decipher will essentially depend on how broad-band a measurement one can make and on the spacing of the recording stations. We feel that a significantly greater number of fault elements (i.e., significantly greater detail of the dislocation amplitudes) than the number used in this work (Figure 4) might not be justified with the presently available data and theory and because virtually nothing is known about the proper choice of $D_{i}\left(\xi_{1}, \xi_{2}, t\right)$ which is, at best, modeled only roughly by (2). Since the fitting of the calculated displacements to the measured ground displacements will tend to emphasize the final dislocation amplitudes and will be less sensitive to the rise time $T$ (see equation (2)) and the shape of the assumed $D\left(\xi_{1}, \xi_{2}, t\right)$, it was decided to work with displacements. It is certainly important for a better understanding 
of the fracturing process to determine a more realistic shape of $D\left(\xi_{1}, \xi_{2}, t\right)$ than given by (2). This is, however, beyond the scope of this preliminary investigation where we focus on the gross features of faulting as portrayed through the final dislocation amplitudes.

It seems intuitively clear that the rise time $T$ is related to the effective stress as defined by Brune (1970) and the final dislocation amplitude. However, to apply the fitting procedure outlined above, it is necessary to choose $T$ for each fault segment before computing the "best" amplitudes $a_{k}$. This results in the variation of the slope of $D_{i}\left(\xi_{1}, \xi_{2}, t\right)$ which becomes $\left(a_{k}^{2}+a_{k+K}^{2}\right)^{1 / 2} / T$ and is different for each $k$ th fault element. The rise time used for the final dislocation model in this study is $0.7 \mathrm{sec}$, but, since the rise time is only a minor parameter for the theoretical wave forms, any value between about 0.5 and $1 \mathrm{sec}$ would also fit the data.

It was already pointed out that the accuracy of the instrument and base-line corrected strong-motion accelerograms is good only in the frequency band between $0.07 \mathrm{~Hz}$ and $25 \mathrm{~Hz}$. For specialized research applications, these limits may be altered on the basis of the required accuracy, the particular nature of the recording instrument, and the desired degree of conservatism. Thus, in spite of the fact that the quality of the original accelerogram used in this study ranks among the best ever recorded, we decided to use the data only between 0.11 and $25 \mathrm{~Hz}$ in order to maximize the dependability of the selected dislocation model. In particular, the Ormsby filter was selected with $f_{T}=0.10 \mathrm{~Hz}$ and $f_{c}=0.12 \mathrm{~Hz}$ (Trifunac, 1971a), and the calculated displacement curves (Trifunac et al., 1973b, c; Brady et al., 1973) were high-pass filtered before the least-squares fitting was performed. To allow for a physically meaningful least-squares procedure, the calculated displacements $u_{i, j, k, l}$ were also high-pass filtered with the identical Ormsby filter before the coefficients $A_{m, m}, A_{m, n}$, and $b_{m}$ were calculated. Once the "best" $a_{k}$ amplitudes are found, it is possible to add the contributions from the unfiltered $u_{i, j, k, l}$ displacements and, thus, calculate the theoretically predicted ground motions that include the D.C. components of displacement as well.

The total of 41 different fault shapes were tested before the "best" model shown in Figure 4 could be found. If different trials within each assumed fault shape are also included in the total number of models tested, including the trials for the best origin time and the dislocation velocities, the total number of models tested is well over 60 .

Although the basic feature of the least-squares approach is to minimize the meansquared deviations between the measured and the filter quantities, it is clearly not possible to fit all measured points exactly. Furthermore, it is seen from the equations (4) that for every set of computed displacements $u_{i, j, k, l}$ there will be a set of $a_{k}$ amplitudes. Thus, the question arises as to what is the basic criterion to be used in selecting the "best" model from a finite number of those tested. It appears that a rather sensitive criterion that can be used for this purpose is the general consistency of the average dislocation vectors for each of the fault elements (Figure 4). For a given model to be acceptable, we thus require that these average vectors be roughly parallel. As may be seen in Figure 4, which shows the "best" dislocation model that could be found in this study, with essentially only one exception, all dislocation vectors are roughly consistent.

One difficulty in using the strong-motion accelerograms for the source mechanism studies is that each instrument is triggered independently and does not register the absolute or common time in any form so that the relative positioning in time of several accelerograms, recorded during the same earthquake, does present a problem. However, it should be mentioned here that this deficiency developed as a result of the extended use of these instruments in the source mechanism studies for which application those accelerographs were originally not intended. At the time of their development, the primary use for these instruments was to record the strong motion in structures and 
various geological conditions, thus providing the basic data for engineering assessment of severe earthquake motions. The relative positioning of measured ground motions and those computed for each model was based on the interpretation of the $S$-wave arrival. Table 2 gives the estimated relative $S$ times measured from the instant each instrument triggered. The first second of calculated displacements at the Castaic Old Ridge Route site (Trifunac et al., 1973c) was not used in this work since, at $0.97 \mathrm{sec}$ after triggering, the drive mechanism malfunctioned briefly and the film was stationary for a short length of time. In this study, we assume that the $S$-wave arrives at $0.0 \mathrm{sec}$ of the adjusted displacement record.

Figure 5 shows the comparison of displacements calculated for the "best" dislocation model (Figure 4) and the displacements derived from the recorded accelerograms. This figure also presents all points (42 in each component, one every $0.5 \mathrm{sec}$ ) used in the least-
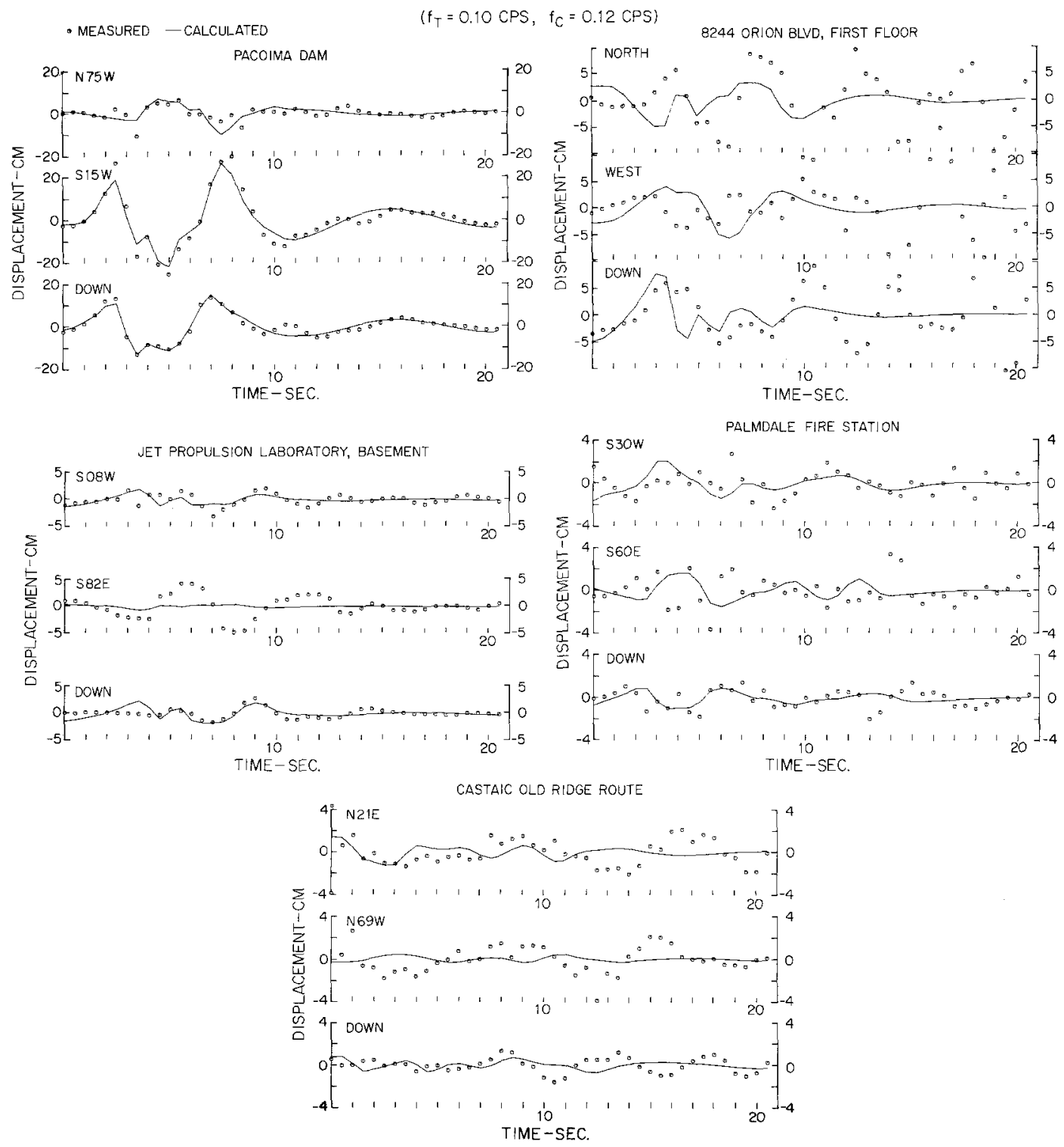

FIG. 5. Comparison of measured and calculated ground displacements (high-pass filtered) during the San Fernando, California, earthquake of February 9, 1971. 
squares fitting (equation (4)). To what extent the recorded motions (Figure 5) contain the contributions from surface waves is difficult to estimate since the geometry of the geological setting of the San Fernando earthquake is quite complicated. In this preliminary work, we make a simplifying assumption that the surface-wave contributions are negligible during the first 10 to $12 \mathrm{sec}$ of strong motion. More detailed studies using the three-dimensional finite element approach should eventually resolve this question. Figure 6 shows that at some stations ( 8244 Orion Blvd.) surface-wave motions or the breakout phases (Hanks, 1973) may have been significant after 10 to $12 \mathrm{sec}$.

How well the recorded and calculated ground motions agree is, of course, a subjective matter of judgment, but we suggest that the agreement for the Pacoima Dam site is very good and fair for all other stations. Some discrepancies between the recorded and calculated displacements at the 8244 Orion Blvd. site might be explained by the effects of the soft alluvial deposits underlying this station, thus, leading to the wave-incidence angle significantly different from the one that would be predicted by the simple infinite space model. This tentative explanation emerges from the perusal of the measured and calculated motions in Figure 5, suggesting that a better fit could be obtained by taking a linear combination of all computed motions to fit each of the measured components.
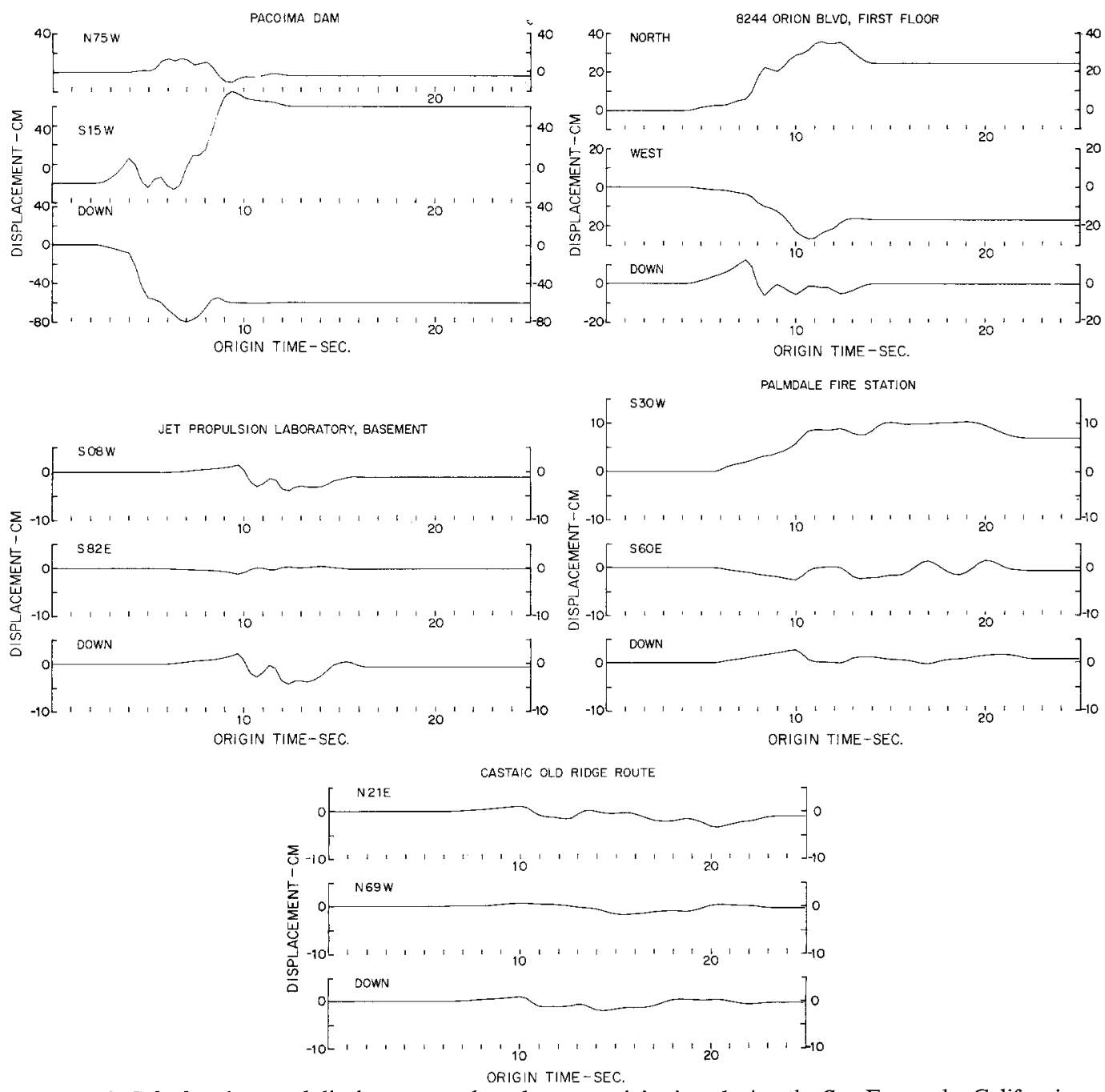

FIG, 6. Calculated ground displacements plotted versus origin time during the San Fernando, California, earthquake of February 9, 1971. 
The $\mathrm{S} 82^{\circ} \mathrm{E}$ component of ground motion recorded in the basement of the Jet Propulsion Laboratory could not be fitted with the chosen dislocation model. Although the first $5 \mathrm{sec}$ of measured and calculated motions agree, the long-period swing starting at about $5 \mathrm{sec}$ is not present in the computed displacements. This disagreement is especially difficult to interpret since the measured $\mathrm{S} 08^{\circ} \mathrm{W}$ and DOWN components at the same station agree well with those calculated from the model. The base of the building which houses this station is $220^{\prime}$ by $40^{\prime}$, and the $\mathrm{S} 82^{\circ} \mathrm{E}$ component is in the longitudinal direction of the building. Whether this discrepancy would be explained by the soilstructure interaction calls for a detailed analysis which is beyond the scope of the present paper.

\section{Comparison of the Dynamic Dislocation Model with other Studies}

The dynamic dislocation model employed in this analysis has three weak characteristics. First, like any other approach to the source-mechanism analysis based on surface observations only, it results in a nonunique inverse problem solution. Second, it is based on the approximate representation (1) which violates the half-space boundary conditions and neglects the contributions from surface waves, the effect of the geological discontinuities, and surface topography. Third, it uses the band-limited record of ground motion, $0.11 \mathrm{~Hz}$ to $25 \mathrm{~Hz}$. In the light of these limitations, it is, therefore, of particular interest to compare the results obtained from the above described dynamic dislocation modeling with the results from other static and dynamic analyses.

To this date, several static dislocation studies were carried out for the San Fernando earthquake. Savage et al. (1972) calculated the changes in length between 16 stations following the earthquake. Figure 7 summarizes the position of their network relative to

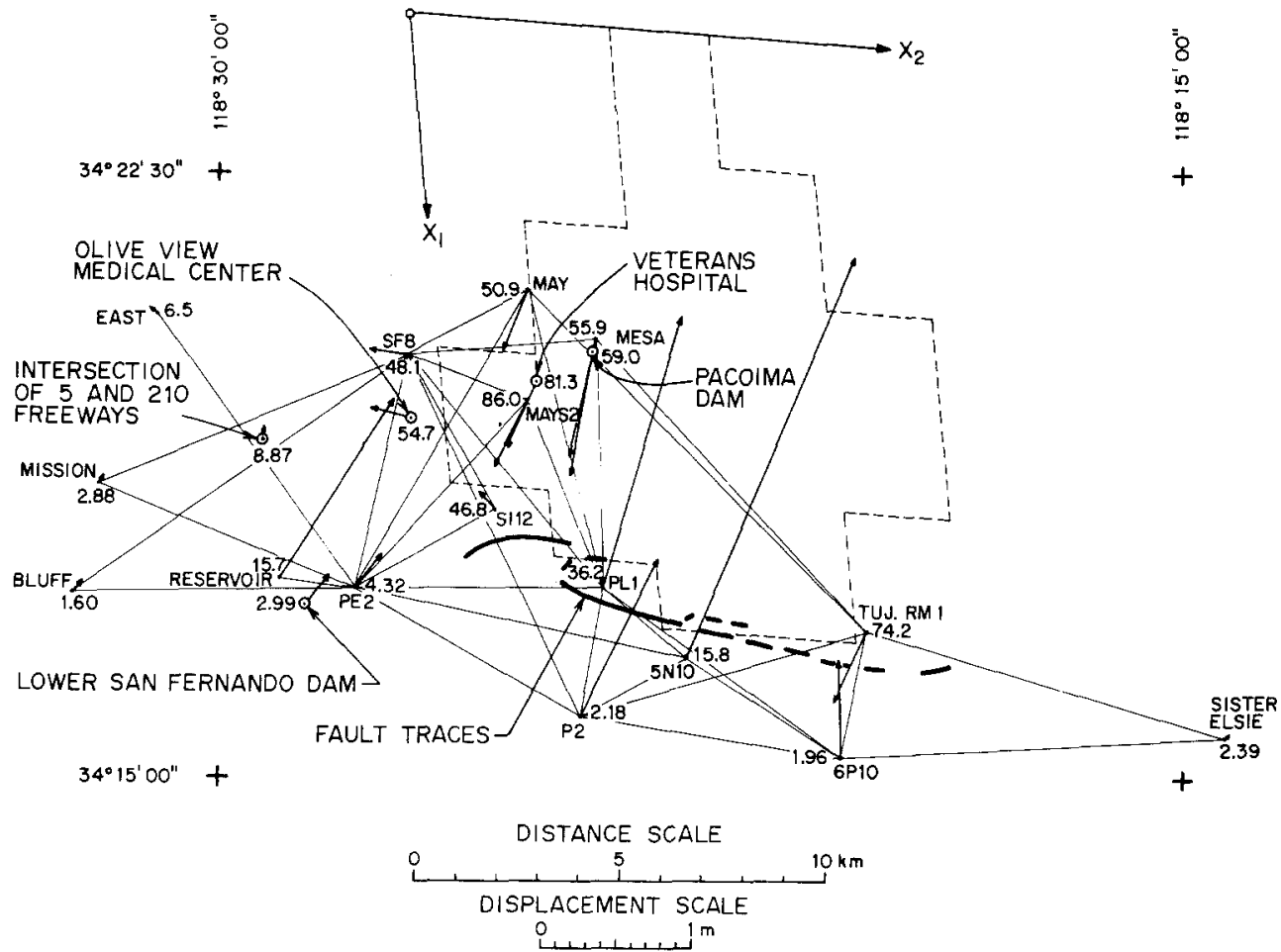

FIG.7. Horizontal-static displacements at the points of the trilateration network (Savage et al., 1972) resulting from the selected dynamic dislocation model (outlined by the dashed line) in Figure 4 . (San Fernando, California, earthquake of February 9, 1971.) 
the horizontal projection of the "best" dislocation model employed in this study. We calculated the permanent displacement for the same set of points, and the displacements are shown by arrows in the same figure. As pointed out by Savage et al. (1972), comparison of the pre- and post-earthquake geodetic surveys yields only the relative displacements of the stations, while any rigid body motion may be applied to the net as a whole without changing the relative displacements. For this reason, the particular choice of the rigidbody motion selected by Savage et al. (1972) agrees only roughly with the permanent displacements calculated from the dynamic dislocation model and the quantitative fit is not good. Furthermore, the approximate nature of our model violating the surface boundary conditions, especially near the surface faulting, does not justify the direct comparison for points such as PLl, for example, that lie on the fault. The points close to the fault surface rupture must be significantly affected by the irregular surface breaks

TABLE 3

Comparison of Measured and Calculated Changes in Length

\begin{tabular}{|c|c|c|c|c|c|c|c|}
\hline \multirow[t]{2}{*}{ Station 1} & \multirow[t]{2}{*}{ Station 2} & \multicolumn{2}{|c|}{ Change in Length (m) } & \multirow[t]{2}{*}{ Station 1} & \multirow[t]{2}{*}{ Station 2} & \multicolumn{2}{|c|}{ Change in Length (m) } \\
\hline & & Measure* & Calculation & & & Measure* & Calculation \\
\hline $\mathrm{P} 2$ & $5 \mathrm{~N} 10$ & 0.13 & 1.30 & SF 8 & $\mathrm{P} 2$ & -0.27 & -0.55 \\
\hline PE2 & Bluff & 0.32 & 0.11 & SF8 & PE2 & 0.03 & -0.27 \\
\hline PE2 & East & 0.29 & -0.03 & SF8 & Reservoir & 0.04 & -1.49 \\
\hline PE2 & May & -0.37 & -0.71 & SF8 & SI12 & -0.44 & 0.02 \\
\hline PE2 & Mays 2 & -0.38 & -0.76 & TUJ. RM1 & May & 0.33 & 0.02 \\
\hline PE2 & Mission & 0.41 & 0.07 & TUJ. RM1 & Mesa & 0.41 & -0.24 \\
\hline PE2 & $\mathrm{P} 2$ & -0.21 & -0.09 & TUJ. RM1 & $\mathrm{P} 2$ & -0.55 & -1.11 \\
\hline PE2 & Reservoir & 0.38 & -0.49 & TUJ. RMI & SF8 & 0.40 & 0.29 \\
\hline PE2 & SI12 & -0.79 & -0.29 & TUJ. RM1 & Sister Elsie & 0.12 & 0.08 \\
\hline $\mathrm{PE} 2$ & $5 \mathrm{~N} 10$ & 0.14 & 0.47 & TUJ. RM1 & $5 \mathrm{~N} 10$ & -0.49 & -1.77 \\
\hline PL1 & May & -1.32 & -1.89 & $6 \mathrm{P} 10$ & $\mathrm{P} 2$ & -0.03 & -0.45 \\
\hline PLl & Mays 2 & -1.24 & -1.75 & $6 \mathrm{P} 10$ & PL1 & 1.89 & 0.20 \\
\hline PL1 & Mesa & -1.23 & -2.49 & $6 \mathrm{P} 10$ & Sister Elsie & 0.11 & 0.01 \\
\hline PL1 & $\mathbf{P} 2$ & -0.10 & 0.72 & $6 \mathrm{P} 10$ & TUJ. RM1 & -0.97 & -1.11 \\
\hline PL1 & PE2 & -2.06 & 0.35 & $6 \mathrm{P} 10$ & $5 \mathrm{~N} 10$ & 0.01 & 0.07 \\
\hline PL1 & SF8 & -1.58 & -0.79 & & & & \\
\hline PL1 & $5 \mathrm{~N} 10$ & 1.67 & -0.04 & & & & \\
\hline SF8 & Bluff & -0.11 & -0.28 & & & & \\
\hline SF8 & May & -0.21 & -0.13 & & & & \\
\hline SF8 & Mays 2 & -0.15 & 0.19 & & & & \\
\hline SF8 & Mesa & -0.60 & 0.01 & & & & \\
\hline SF8 & Mission & -0.02 & -0.27 & & & & \\
\hline
\end{tabular}

*From Savage et al. (1972).

(Figure 2) and the subsidiary fault (Sharp, 1972) so that their final displacements cannot be modeled by a single dislocation plane used in this study. However, the comparison of the measured and calculated changes in length between the selected points (Figure 7) should be in qualitative agreement if our dislocation model is to be accepted, and, as Table 3 indicates, for about one half the points compared, the measured and calculated changes in horizontal distance are within a factor of about two. Considering the accuracy of the methods employed and, in particular, the approximate nature of the fault geometry consisting of the rectangular elements, with each element contributing by a constant dislocation amplitude, we feel that the agreement between the calculated and measured changes of length is fair. 
Figure 8 compares the observed vertical displacements (Alewine and Jordan, 1972) with the vertical displacements calculated for our best dislocation model at all points shown in Figure 7. Although the 21 points do not depict the details of vertical displacement resulting from the theoretical model, the overall agreement with measured vertical displacements appears to be good.

The fault-plane solutions derived from the body-wave data (Table 1) sampling the fault geometry during the first few seconds indicate a fault plane dipping at an angle of $52^{\circ}$. On the other hand, the surface and near-surface fault expression (e.g., Kamb et al., 1971; Proctor et al., 1972) suggest a shallow dipping fault $\left(20^{\circ}\right.$ to $\left.25^{\circ}\right)$. Combined with the distribution of aftershocks, this evidence suggests that the dislocation surface was curved. As suggested by Hanks (1973), this interpretation would lead to the shallow section of the fault dipping about $30^{\circ}$ to $35^{\circ}$ for about $10 \mathrm{~km}$ which, at the depth of about $5 \mathrm{~km}$, steepens to about $52^{\circ}$ and extends for another $8 \mathrm{~km}$ down to the hypocenter at the

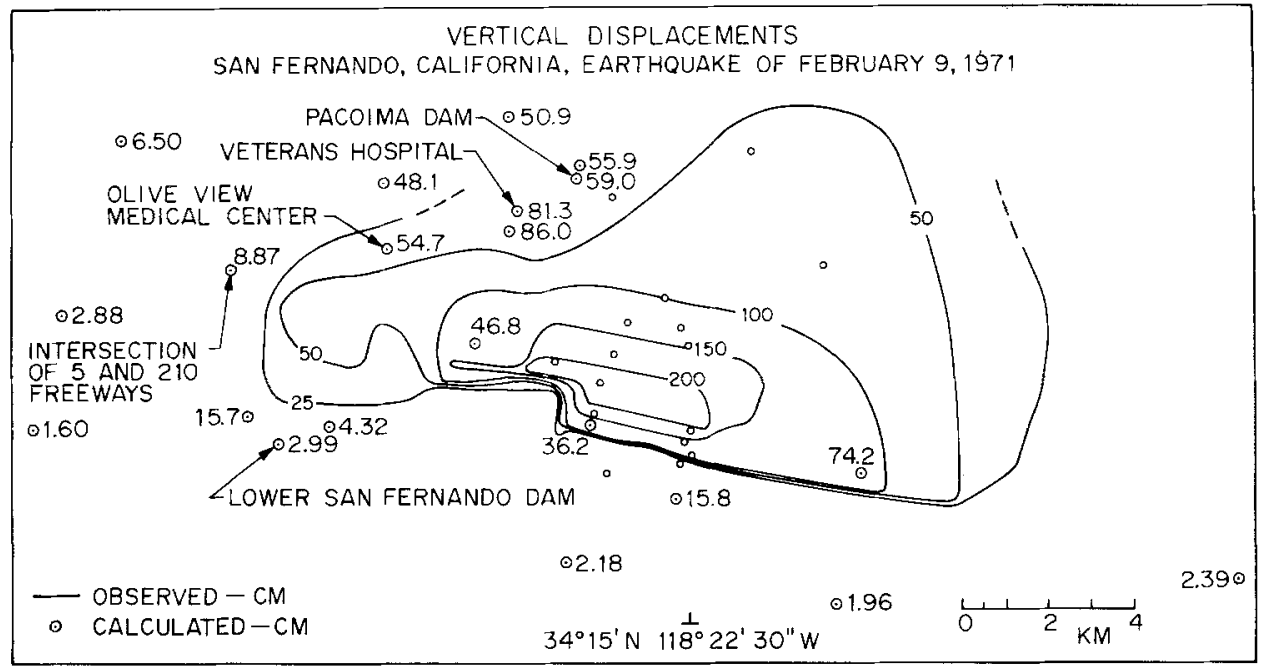

Frg. 8. Comparison of observed (Alewine and Jordan, 1972) and calculated vertical displacements following the San Fernando earthquake.

depth of $12 \mathrm{~km}$. The static dislocation models of Jungels (1973) and Alewine and Jordan (1972), developed around the curved fault-plane assumption, reinforce this interpretation by showing that such a fault model does lead to a good fit of the observed static displacements on the free surface. In studying the dynamic dislocation model based on the recorded strong-motion accelerograms, we feel that the resolution provided by the five strongmotion stations might not be adequate to distinguish between a plane and the curved fault surface, and we assume a plane fault with a dip of $40^{\circ}$. Two other fault models with dips of $33^{\circ}$ and $47^{\circ}$, and with all other parameters identical to those for the "best" model with the dip of $40^{\circ}$, were fitted to the data. The model with a dip of $40^{\circ}$ proved to be the best in that it gave the set of dislocation vectors (Figure 4) that were mutually more consistent in their directions.

Only one, central and eastern, elementary dislocation (Figure 4), with the amplitude of the average dislocation vector of $3.7 \mathrm{~m}$, leads to a direction of the dislocation vector that is significantly different from the average orientation of all other arrows in Figure 4. While this deviation from the average trend may result from many sources of "noise" in the chain of the fitting procedures, it is interesting to note here that, for numerous trials 
during the search for the "best" model, this section of the fault almost always led to the dislocation vector roughly parallel to the one shown in Figure 4. This suggests a speculative interpretation that some tearing may have taken place along a plane roughly vertical and perpendicular to the fault plane. In connection with this observation we quote from Savage et al. (1972):

A north-south oblique-slip tear fault in the hanging wall block connecting the east end of the Sylmar segment with the west end of the Tujunga segment is postulated on the basis of the pattern of surface faulting and vertical movement. The possible tear fault would have a vertical slip component of perhaps $2 \mathrm{~m}$ with the east side up, combined with right-lateral and east-west contractional components of about the same amount.

The possible occurrence of tensile faulting certainly contributes to the difficulties of discriminating underground nuclear explosions from earthquakes. Therefore, one of the objectives behind the dynamic dislocation modeling of earthquakes is to find to what extent such faulting can be identified through the detailed analysis of recorded wave forms. For the San Fernando earthquake, we use the shear dislocation model and one fault plane only because the available strong-motion data and the complexity of geological strata between the source and the recording stations seem not to warrant the dynamic modeling of splay faults near the surface (Alewine and Jordan, 1972), a curved fault surface (Hanks, 1973), or possible north-south tear faulting between the San Fernando and Tujunga surface fractures. With dense arrays of strong-motion accelerographs, it will be possible to decipher the details of evolving dislocation in much greater detail and to model earthquakes with multiplanar dislocations if necessary.

In spite of the fact that different investigators have used plane or curved fault planes and the two- or three-dimensional theory, it is useful to compare the overall trends of the computed dislocation amplitudes with the dynamic model developed in this study. Such a comparison can increase our confidence in the methods that give consistent results and at the same time can offer a way to roughly measure the reliability of each individual approach. Figure 9 compares our three-dimensional dynamic analysis with the results of Jungels (1973), who fitted the vertical surface displacements along the sections AA and $\mathrm{BB}$ (Figure 1) with the two-dimensional curved fault plane, and with the results of Alewine and Jordan (1972), who fitted the vertical observations with a three-dimensional static model. Although the direct comparison is not possible, because the fault widths are different for the three models, the general pattern appears to be consistent for both static and dynamic models. These results indicate large dislocation amplitudes in the hypocentral region ranging from about 4 to $12 \mathrm{~m}$, gradual decrease of amplitudes with the minimum of about 1 to $3 \mathrm{~m}$ half-way between the hypocenter and the surface fractures, and the build up of dislocation amplitudes to about 2 to $7 \mathrm{~m}$ just before the fault breaks the surface. As pointed out by Alewine and Jordan (1972), these large amplitudes were most probably attenuated near the surface through the formation of numerous splay faults. Contrary to Mikumo (1973) who suggests rather small dislocation amplitudes in the hypocentral region $(10-30 \mathrm{~cm})$, we believe that the initial rupture near the hypocenter should be characterized by large dislocations of the order of 5 to $10 \mathrm{~m}$. The large displacements inferred here for the hypocentral region fully agree with those estimated by Hanks (1973) and moreover have been recognized as admissible by Alewine and Jordan (1972) and Jungels (1973).

To satisfy the free surface conditions, the dislocation front, as it hits the half-space boundary, should generate the reflected dislocation of the same amplitude but with the 
opposite direction of propagation. This phenomenon should lead to the two-fold increase of the surface-fault offsets, which would gradually diminish away from the surface and should extend the duration of shaking. It is tempting to examine this possibility further because the recorded ground displacements, after the first 10 to $12 \mathrm{sec}$, especially at the 8244 Orion Blvd, site, show significant deviations from the fitted theoretical model (Figure 5) perhaps not entirely caused by surface waves. Several models were fitted to the data in Figure 5, and the results indicated that this interpretation is quite possible. However, since it is very difficult to find at which point the upcoming dislocation first intersected the surface, it is hard to find the direction and the initial time of reflected dislocations along the surface breaks (Figure 1). Since the geometry of the alluvial deposits in the San Fernando Valley undoubtedly further complicates the recorded motions, it was decided to leave this problem for a more detailed future investigation.

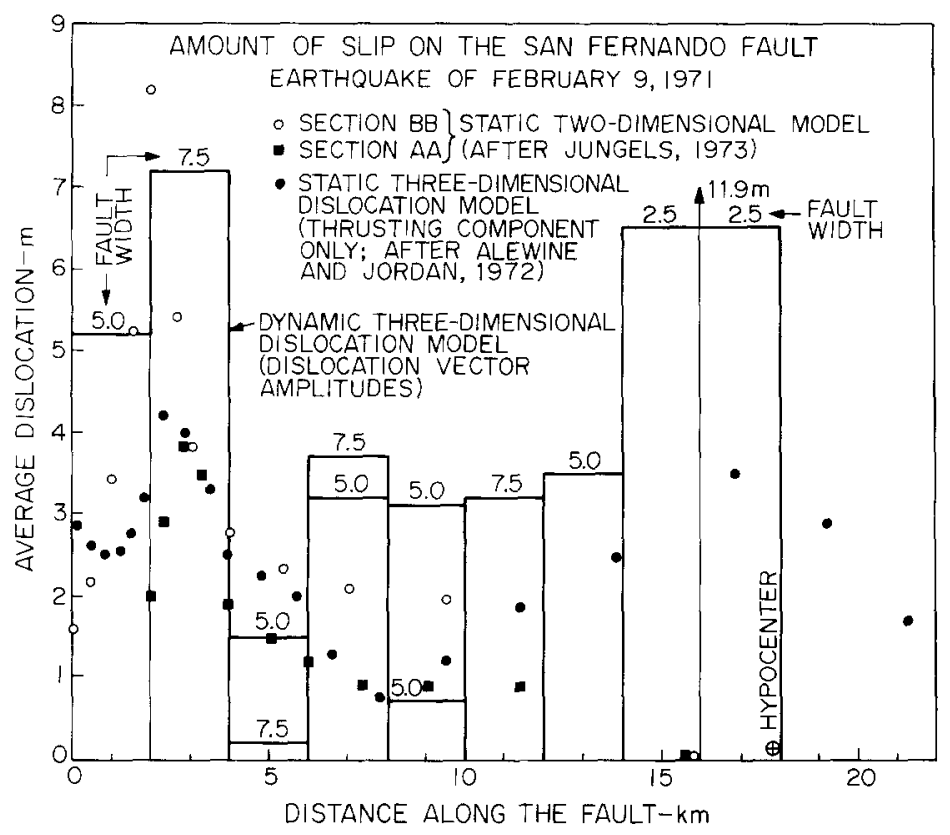

FIG. 9. Comparison of the dynamic dislocation amplitudes (Figure 4) with the results of (a) Jungels' (1973) two dimensional, finite element, static analysis of thrusting amplitudes for sections AA and BB (Figure 1) and (b) static three-dimensional dislocation model of Alewine and Jordan (1972) based on the thrusting component only.

Hanks (1973) recently suggested that the point of initial rupture may be some $4 \mathrm{~km}$ further north and $4 \mathrm{~km}$ deeper than the hypocenter of Allen et al. (1972) $\left(37^{\circ} 24.7^{\prime} \mathrm{N}\right.$, $118^{\circ} 24.0^{\prime} \mathrm{W}$, depth $\left.(h)=8.4 \mathrm{~km}\right)$. His suggestion is based on the tentative identification of the $p P$ phase at teleseismic distances and the detailed analysis of $S-P$ times from the radiation emanating from the point of the initial rupture. The $S-P$ time for the Pacoima Dam accelerogram is at least $2.1 \mathrm{sec}$, and for a $P$-wave velocity of $5.6 \mathrm{~km} / \mathrm{sec}$ and the $S$-wave velocity of $3.2 \mathrm{~km} / \mathrm{sec}$, the hypocentral distance would be about $15 \mathrm{~km}$. This would place the epicenter about $2 \mathrm{~km}$ farther than indicated by the epicenter of Allen et al. (1971) $\left(34^{\circ} 24.0^{\prime} \mathrm{N}, 118^{\circ} 23.7^{\prime} \mathrm{W}\right.$, depth $(h)=13.0 \mathrm{~km}$ shown in Figure 1) which is about $6 \mathrm{~km}$ north from the Pacoima Dam.

To examine this suggestion (Hanks, 1973), we tested the dislocation model that had the same fault shape as in Figure 1 but was "stretched" in the $x_{1}$ direction so that the 
fault segments are 2.5 instead of $2 \mathrm{~km} / \mathrm{sec}$ (Figure 4). The southernmost end of this fault was assumed to be the same as for our final dislocation model while the hypocenter was moved by $4.5 \mathrm{~km}$ in the negative $x_{1}$ direction (Figure 1). With all other parameters identical to those indicated in Figure 4, this model leads to the source whose duration was the same as that of our final model in Figure 4. When fitted to the measured ground displacements, the resulting dislocation amplitudes were not consistent with each other in that the dislocation vectors were not mutually parallel and had several components in the negative $x_{1}$ direction, so that this model had to be rejected. While this single test indicates that the dislocation model shown in Figures 1 and 4 appears to fit the observed ground motion in a way more consistent with the basic assumptions in this analysis, it must be remembered that our solution is not unique and that Hanks' (1973) suggestion cannot be ruled out on the basis of this one trial only. It may be that the dislocation was initiated several kilometers to the north of the epicenter of Allen et al. (1972), but to find further evidence for that it would be necessary to test many additional dislocation models that propagate with nonuniform velocity, which would be required to arrive at the consistent dislocation vectors. This possible refinement is beyond the scope of this paper.

\section{Ground Displacements in the Severely Damaged Area}

The urban area subjected to the strongest shaking during the San Fernando earthquake is shown in Figure 2. Fifty-nine people lost their lives because of the damage caused by the earthquake. Of those, 46 were killed in the Veterans Administration Hospital, two were killed by a collapsing freeway overpass, and four died in their homes. Six people died from causes directly related to the earthquake (Jennings, 1971).

There were no strong-motion accelerographs in the area of severe damage. The nearest two instruments (Figure 2) were located at the Pacoima Dam and at the intersection of Roscoe and Freeway 405, too far to be of direct use in the structural analysis of collapsed buildings (Veterans Administration Hospital), severely damaged buildings (e.g., Olive View Medical Center), collapsed freeway overpasses (Intersection of freeways 5 and 210), and a dam (Lower San Fernando Dam), to name only a few. This lack of instrumentation in the damaged area represents a serious omission of the programs aimed at the assessment and reduction of earthquake disasters, since the San Fernando earthquake may be taken as an object lesson indicating what might happen if such an earthquake were to occur, for example, in downtown Los Angeles.

To shed some light on the nature of strong shaking at the sites of some of the severely damaged structures, we calculated the ground motion at four locations (Veterans Administration Hospital, Olive View Medical Center, Lower San Fernando dam, and the Intersection of Freeways 5 and 210) using the dislocation model described in this study. Figure 10 shows the computed ground displacements plotted versus the origin time. We believe that these displacement curves describe roughly the actual ground motion during the first 10 to $12 \mathrm{sec}$. To estimate the accuracy of these curves, one can use the results in Figure 5 as a qualitative measure of the agreement between the measured and computed ground motions. Because the 8244 Orion Blvd. station is located on the San Fernando Valley alluvium and is quite far to the south, it may be assumed that the agreement between the actual and computed ground motions in Figure 10 is more of the nature indicated by the Pacoima Dam records.

In a brief conversation with the night guard, who was in his office on the ground floor of the Olive View Medical Center when the earthquake struck, it was learned that while he was sitting at his desk, he was thrown upward, together with his table and chair, two times in succession during a time interval of about several seconds. When further asked, 

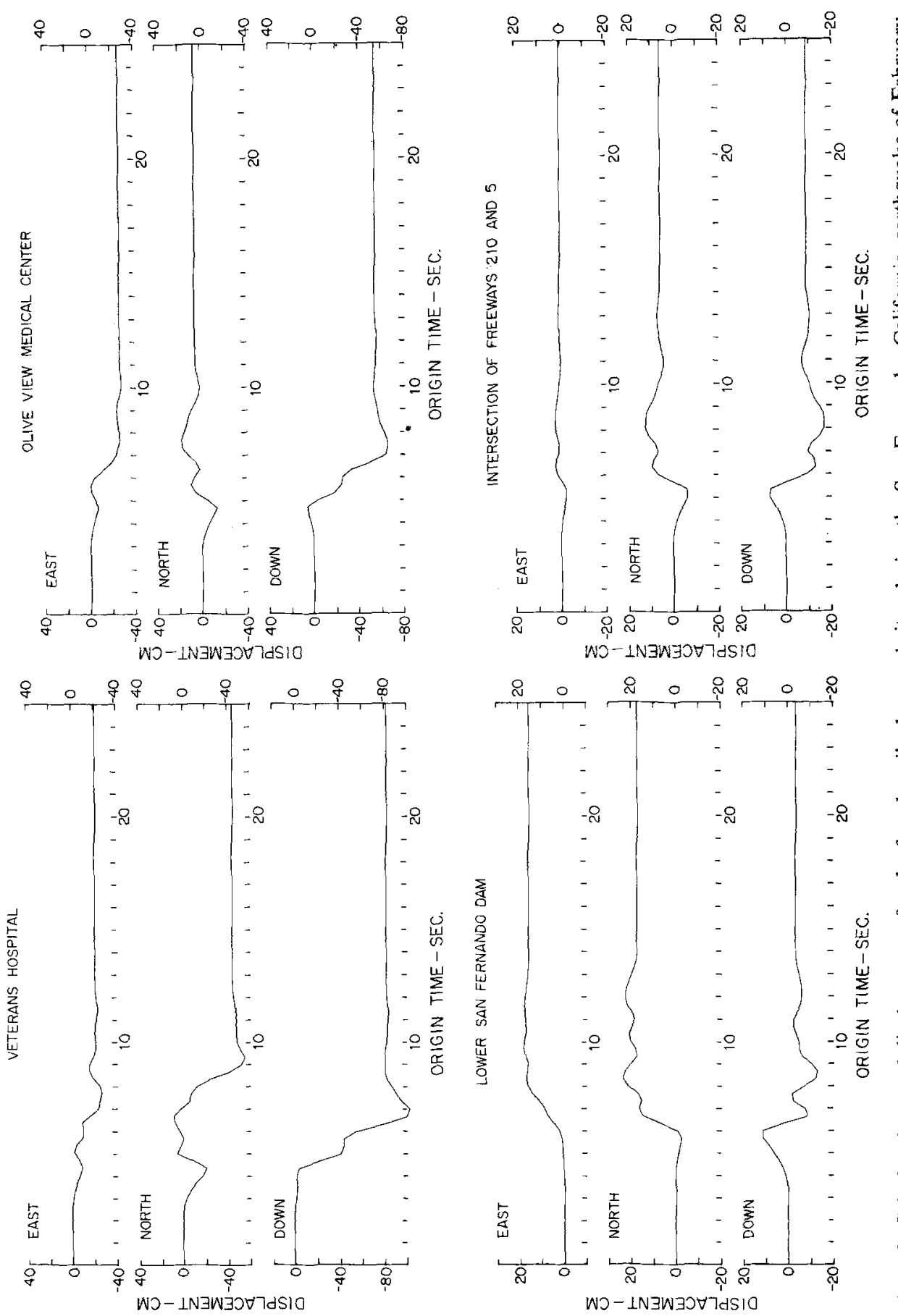

要 
he said that the shaking was indeed strong in all directions but that the only prominent features that he could remember were those two vertical throws. Having analyzed the available strong-motion data and the ground displacement calculated for the Olive View Medical Center site (Figure 10), this account becomes more plausible than it seemed 2 years ago.

The ground motions presented in Figure 10 are intended to aid in the qualitative analysis of damage in the severely shaken area during the first 10 to $12 \mathrm{sec}$ only. These motions might be used as a meaningful input for the response calculation of structures whose natural period is longer than 1 or $2 \mathrm{sec}$ but cannot be used for systems with shorter natural periods as previously discussed.

\section{CONCLUSIONS}

The three-dimensional dislocation model described by Haskell (1969) has been examined in this paper as a possible basis for modeling the earthquake fracture process. Using the data from five strong-motion stations surrounding the fault zone of the San Fernando, California, earthquake of February 9, 1971, it has been possible to find a model which approximately correlates with the recorded ground displacements during the earthquake (strong-motion data) with the static deformations after the earthquake (geodetic data) and with the observed faulting in the San Fernando Tujunga area.

Finding the dislocation model for a given earthquake from strong-motion data is a difficult task involving the solution of an inverse problem which has no unique solution. The problem is further complicated by the effects of nonhomogeneous media between the source and the receiver. It appears, however, that by recording the ground motion at distances less than one source dimension, it may be possible to derive a simple approximate source model that can satisfy the dynamic and static measurements of the earthquake effects in the low-frequency band from D.C. to about $1 \mathrm{~Hz}$. For this frequency band, the amplitudes of recorded waves are believed not to be affected seriously by the local geological conditions.

To see how the approximate solution, least-square fitted to the observed data, agrees with the exact dislocation model, we have to wait until such time as when it will be possible to measure dislocation amplitudes at the fault itself. The present analysis shows, however, that until that time comes it is worthwhile (1) to develop the representation of the dynamic dislocation models in a nonhomogeneous half-space and (2) to deploy arrays of strong-motion accelerographs to measure the near-field strong-ground motion. The results of this preliminary analysis already indicate the possibility of deciphering the details of the complicated dislocation processes and demonstrate how valuable the nearfield strong-motion data are for acquiring an understanding of earthquake source mechanism, of prediction of strong ground shaking for earthquake engineering purposes, and for the development of sensitive techniques for discrimination between explosive and tectonic sources.

\section{ACKNOWLEDGMENTS}

I am indebted to R. Alewine, B. Minster, T. C. Hanks, and F. E. Udwadia for critical reading of the manuscript and for offering many valuable suggestions.

This research was supported by the Advanced Research Projects Agency of the Department of Defense and was monitored by the Air Force Office of Scientific Research under Contract F44620-72-C-0097. 


\section{REFERENCES}

Alewine, R. W. and T. H. Jordan (1972). Generalized inversion of earthquake static displacement fields (in press).

Allen, C. R., G. R. Engen, T. C. Hanks, J. M. Nordquist, and W. R. Thatcher (1971). Main shock and larger aftershocks of the San Fernando earthquake, February 9 through March 1, 1971, U.S. Geol. Survey, Profess. Paper 733, 17-20.

Allen, C. R., T. C. Hanks, and T. H. Whitcomb (1972). San Fernando earthquake: Seismological studies and their tectonic implications, Calif. Div. Mines Geol. Bull. (in press).

Boore, D. (1972). The effect of simple topography on seismic waves: Implications for the recorded accelerations at Pacoima Dam, (Abstract) Nat. Conf. Earthquake Eng., Los Angeles.

Brady, A. G., M. D. Trifunac, and D. E. Hudson (1973). Strong motion earthquake accelerograms Vol. II, D, Corrected accelerograms and integrated ground velocity and displacement curves, EERL 73 52, Earthquake Eng. Res. Lab., Calif. Inst. of Tech., Pasadena.

Brune, J. N. (1970). Tectonic stress and the spectra of seismic shear waves from earthquakes, J. Geophys. Res. 75, 4997-5009.

Burford, R. O., R. O. Castle, J. P. Church, W. T. Kinoshita, S. H. Kirby, R. T. Ruthven, and J. C. Savage (1971). Preliminary measurements of tectonic movement, U.S. Geol. Survey, Profess. Paper $733,80-85$.

Burridge, R. and J. R. Willis (1969). The self-similar problem of the expanding elliptical crack in an anisotropic solid, Proc. Cambridge Phil. Soc. 66, 443-468.

De Hoop, A. T. (1958). Representation theorems for the displacement in an elastic solid and their application to elastodynamic diffraction theory, Thesis, Technische Hogeschool, Delft.

Hanks, T. C. (1972). The faulting mechanism of the San Fernando earthquake and identification of the initial rupture radiation, Chapter V of Ph.D. Thesis, Calif. Inst. of Tech., Pasadena.

Hanks, T. C. (1973). The faulting mechanism of the San Fernando earthquake (in press).

Hanks, T. C., T. H. Jordan, and J. B. Minster (1971). Precise locations of aftershocks of the San Fernando earthquake 2300 (GMT) February 10-1700, February 11, 1971, U.S. Geol. Survey, Profess. Paper $733,21-23$.

Haskell, N. A. (1964). Total energy and energy spectral density of elastic wave radiation from propagating faults, Bull. Seism. Soc. Am. 54, 1811-1841.

Haskell, N. A. (1969). Elastic displacements in the near-field of a propagating fault, Bull. Seism. Soc. Am. 59, 865-908.

Hudson, D. E. (1970). Ground-motion measurements, Chapter 6 in Earthquake Engineering, Wiegel, Editor, Prentice Hall, N. J.

Hudson, D. E. (1972). Strong-motion seismology, Proc. Intern. Conf. Microzonation Safer Construction Res. Appl., Seattle, Washington.

Jennings, P. C. (1971) (Editor). Engineering Features of the San Fernando Earthquake, EERL 71-02, Earthquake Eng. Res. Lab., Calif. Inst. of Tech.

Jungels, P. H. (1973). Modeling of tectonic processes associated with earthquakes, Ph.D. Thesis, Calif. Inst. of Tech., Pasadena.

Kamb, B., L. T. Silver, M. J. Abrams, B. A. Carter, T. H. Jordan, and J. B. Minster (1971), Pattern of faulting and nature of fault movement in the San Fernando earthquake, U.S. Geol. Survey, Profess. Paper 733, 41-54.

Kostrov, B. V. (1970). The theory of the focus for tectonic earthquakes, Izv. Akad. Nauk USSR, Solid Earth Physics, 258-267.

Lahr, C., M. Wyss, and J. A. Hileman (1971). Repeated surveys of small scale figures established across surface-fault ruptures following the earthquake, U.S. Geol. Survey Profess. Paper 733, 86-88.

Mikumo, T. (1973). Faulting process of the San Fernando earthquake of February 9, 1971 inferred from static and dynamic near-field displacements, Bull. Seism. Soc. Am. 63, 249-264.

Proctor, R. J., R. Crook, Jr., M. H. McKeown, and R. L. Moresco (1972). Relation of known faults to surface ruptures, 1971, San Fernando earthquake, southern California, Bull. Geol. Soc. Am. 83, $1601-1618$.

Reimer, R. B., R. W. Clough, and J. M. Raphael (1972). Seismic response of Pacoima dam in the San Fernando earthquake (Abstract), Nat. Conf. Earthquake Eng., Los Angeles, California.

Richards, P. (1973). The dynamic field of a growing plane elliptical shear crack (in press).

Salvadori, M. G. and M. L. Baron (1961). Numerical Methods in Engineering, Prentice Hall, N. J.

Savage, J. C., R. O. Burford, and W. T. Kinoshita (1972). Earth movements from geodetic measurements, (in press). 
Sharp, R. V. (1972). Surficial-fault displacement, San Fernando earthquake (in press).

Trifunac, M. D. (1971a). Zero base-line correction of strong motion accelerograms, Bull. Seism. Soc. Am. 61, 1201-1211.

Trifunac, M. D. (1971b). Surface motion of a semi-cylindrical canyon, Intern. J. Earthquake Eng. and Dyn. of Struct. 1, 267-281.

Trifunac, M. D. and D. E. Hudson (1971). Analysis of the Pacoima Dam accelerogram, San Fernando, California, earthquake of 1971. Bull. Seism. Soc. Am. 61, 1393-1411.

Trifunac, M. D. (1972a). A note on correction of strong-motion accelerograms for instrument response, Bull. Seism. Soc. Am. 62, 401-409.

Trifunac, M. D. (1972b). Stress estimates for the San Fernando, California, earthquake of February 9, 1971: Main event and thirteen aftershocks, Bull. Seism. Soc. Am. 62, 721-750.

Trifunac, M. D. (1972c). Tectonic stress and the source mechanism of the Imperial Valley, California, earthquake of 1940, Bull. Seism. Soc. Am. 62, 1283-1302.

Trifunac, M. D. (1973). Scattering of plane $S H$ waves by a semi-cylindrical canyon, Intern. J. Earthquake Eng. and Dyn. of Struct. 1, 267-281.

Trifunac, M. D., F. E. Udwadia, and A. G. Brady (1973a): Analysis of errors in digitized strong-motion accelerograms, Bull. Seism Soc. Am. 63, 157-187.

Trifunac, M. D., A. G. Brady, and D. E. Hudson (1973b). Strong-Motion Earthquake Accelerograms, Vol. IIC, Corrected Accelerograms and Integrated Ground Velocity and Displacement Curves, EERL 73-51, Earthquake Eng. Res. Lab., Calif. Inst. of Tech., Pasadena.

Trifunac, M. D., A. G. Brady, and D. E. Hudson (1973c). Strong-Motion Earthquake Accelerograms, Vol. IIG, Corrected Accelerograms and Integrated Ground Velocity and Displacement Curves, EERL 73-55, Earthquake Eng. Res. Lab., Calif. Inst. of Tech., Pasadena.

U.S. Geological Survey Professional Paper 733 (1971). The San Fernando, California, Earthquake of February 9, 1971, A Preliminary Report, published jointly by the USGS and NOAA.

Wesson, R. L., W. H. K. Lee, and J. F. Gibbs (1971). Aftershocks of the Earthquake, U.S. Geol. Survey Profess. Paper 733, 24-29.

Whitcomb, J. H. (1971). Fault-plane solutions of the February 9, 1971, San Fernando earthquake and some aftershocks, U.S. Geol. Surv. Profess. Paper 733, 30-32.

Wyss, H. (1971). Preliminary source parameter determination of the San Fernando earthquake, U.S. Geol. Surv. Profess. Paper 733, 38-40.

EARTHQUAKe EngINEERING RESEARCh Laboratory

California Institute of Technology

Pasadena, California 91109

Manuscript received June 4, 1973 